PACS 31.15.A-; 32.30.-r

Khetselius O. Yu., Mykhailov, A. L.

Odesa State Environmental University, L’vovskaya str.15, Odesa-16, 65016, Ukraine

E-mail: mykhailovo194@gmail.com

\title{
RELATIVISTIC CALCULATION OF WAVELENGTHS AND E1 OSCILLATOR STRENGTHS IN LI-LIKE MULTICHARGED IONS AND GAUGE INVARIANCE PRINCIPLE
}

\begin{abstract}
The spectral wavelengths and oscillator strengths for $1 \mathrm{~s}^{2} 2 \mathrm{~s}\left({ }^{2} \mathrm{~S}_{1 / 2}\right) \rightarrow 1 \mathrm{~s}^{2} 3 \mathrm{p}\left({ }^{2} \mathrm{P}_{1 / 2}\right)$ transitions in the Li-like multicharged ions with the nuclear charge $\mathrm{Z}=28,30$ are calculated on the basis of the combined relativistic energy approach and relativistic many-body perturbation theory with the zeroth order optimized Dirac-Kohn-Sham one-particle approximation and gauge invariance principle performance. The comparison of the obtained results with available theoretical and experimental (compilated) data is performed. The important point is linked with an accurate accounting for the complex exchange-correlation (polarization) effect contributions and using the optimized one-quasiparticle representation in the relativistic many-body perturbation theory zeroth order that significantly provides a physically reasonable agreement between theory and precise experiment.
\end{abstract}

\section{Introduction}

The development of new directions in the The study of spectroscopic and structural properties of the multicharged ions has a subject of significant interest for many physical, astrophysical and chemical applications. The levels energies, transitions probabilities, oscillator strengths and so on are very important in atomic physics (spectroscopy, spectral lines theory), astrophysics, plasma physics, laser physics, quantum electronics. They are very much needed in research of thermonuclear reactions, where the ionic radiation is one of the primary loss mechanisms and so on. The spectral lines belonging to the radiation of many multicharged ions have been identified in both solar flares and nonflaring solar active regions, observed in high-temperature plasmas, such as pinches and laser-produced plasmas, and in beam-foil spectra. The multiple observations of satellite lines of the He-, Li-, Be-like multicharged ions in the solar corona and in laboratory plasmas have emphasized the need for accurate values of the energetic and spectroscopic parameters for multicharged ions. [1-10].

However, a study of the spectral characteristics of heavy atoms and ions in the Rydberg states has to be more complicated as it requires a necessary accounting for the rela- tivistic, exchange-correlations effects and possibly the QED corrections for superheavy atomic systems. The simultaneous correct accounting of relativistic, quantum electrodynamic (QED), and many-particle correlation effects is essential [11-40]. The results of calculating the characteristics of atomic processes based on modern theoretical methods often differ several times.

The difference in the values of the transition amplitudes, the oscillator strengths, and the radiation widths for heavy atoms using various expressions for the photon propagator reaches 5-30\% (we are essentially talking about the non-fulfillment of the principle of gauge invariance when calculating physical quantities) [11-18]. From the point of view of applications for the majority of the most important atomic systems, there is very often partially or completely missing information on their energy, radiation or/and autoionization characteristics (heavy atoms, atoms of alkaline-earth elements, lanthanides and actinides).

In this paper The spectral wavelengths and oscillator strengths for $1 \mathrm{~s}^{2} 2 \mathrm{~s}\left({ }^{2} \mathrm{~S}_{1 / 2}\right) \rightarrow$ $1 \mathrm{~s}^{2} 3 \mathrm{p}\left({ }^{2} \mathrm{P}_{1 / 2}\right)$ transitions in the Li-like multicharged ions with the nuclear charge $\mathrm{Z}=28,30$ are calculated on the basis of the combined relativistic energy approach and 
relativistic many-body perturbation theory with the zeroth order optimized Dirac-KohnSham one-particle approximation and studying an effect of the gauge invariance on the transition amplitude values for some Li-like multicharged ions.

\section{Relativistic theory of multicharged ions}

In Refs. [2-5,.8,16-25] the fundamentals of the relativistic many-body PT formalism have been in detail presented, so further we are limited only by the novel elements. Let us remind that the majority of complex atomic systems possess a dense energy spectrum of interacting states. In Refs. [16-24] there is realized a field procedure for calculating the energy shifts $\Delta \mathrm{E}$ of degenerate states, which is connected with the secular matrix $M$ diagonalization. The whole calculation of the energies and decay probabilities of a nondegenerate excited state is reduced to the calculation and diagonalization of the $M$. The complex secular matrix $M$ is represented in the form:

$$
M=M^{(0)}+M^{(1)}+M^{(2)}+M^{(3)} .
$$

where $M^{(0)}$ is the contribution of the vacuum diagrams of all order of PT, and $M^{(1)}$, $M^{(2)}, M^{(3)}$ those of the one-, two- and three$\mathrm{QP}$ diagrams respectively. The diagonal matrix $M^{(1)}$ can be presented as a sum of the independent 1QP contributions. The optimized 1-QP representation is the best one to determine the zeroth approximation. In the relativistic energy approach, which has received a great application during solving numerous problems of atomic, molecular and nuclear physics (e.g., see Refs. [16-54]), the imaginary part of electron energy shift of an atom is directly connected with the radiation decay possibility (transition probability). An approach, using the Gell-Mann and Low formula with the QED scattering matrix, is used in treating the relativistic atom. The total energy shift of the state is usually presented in the form:

$$
\Delta \mathrm{E}=\operatorname{Re} \Delta \mathrm{E}+\mathrm{i} \Gamma / 2
$$

where $\Gamma$ is interpreted as the level width, and the decay possibility $\mathrm{P}=\Gamma$. The imaginary part of electron energy of the system, which is defined in the lowest order of perturbation theory as [16-20]:

$$
\operatorname{Im} \Delta E(B)=-\frac{e^{2}}{4 \pi} \underset{\substack{\alpha>n>f \\ \alpha<<n \leq f]}}{\sum V_{\alpha n \alpha n}^{\left|\omega_{\alpha n}\right|},}
$$

where $(\alpha>n>f)$ for electron and $(\alpha<n<f)$ for vacancy. The matrix element is determined as follows:

$V_{i j k l}^{|\omega|}=\iint d r_{1} d r_{2} \Psi_{i}^{*}\left(r_{1}\right) \Psi_{j}^{*}\left(r_{2}\right) \frac{\sin |\omega| r_{12}}{r_{12}}\left(1-\alpha_{1} \alpha_{2}\right) \Psi_{k}^{*}\left(r_{2}\right) \Psi_{l}^{*}\left(r_{1}\right)$

where $\omega_{i j}$ is the transition frequency; $\alpha_{i}, \alpha_{j}$ are the Dirac matrices. The separated terms of the sum in (1) represent the contributions of different channels and a probability of the dipole transition

Naturally, the physical values should not depend on the calibration of the photonic propagator. In general form, it can be written as

$$
\begin{gathered}
D=D_{T}+C \cdot D_{L}, \\
D_{T}=\frac{\delta_{\mu v}}{k_{0}^{2}-k^{2}}, \\
D_{L}=\frac{k_{\mu} k_{v}}{k_{0}^{2}-k^{2}}
\end{gathered}
$$

where the term $D_{T}$ is corresponding to exchange by transverse photons, $D_{L}$ - longitudinal ones, $\mathrm{C}$ is the gauge constant. contribution of the main exchange-correlation (the second and higher orders of the atomic perturbation theory or fourth etc of the QED perturbation theory) diagrams to imaginary part of an electron energy shift looks like [17]:

$$
\begin{aligned}
& \operatorname{Im} E_{n i n v}\left(\alpha-s \mid A_{d}\right)=-C \frac{e^{2}}{4 \pi} \iiint \int d r_{1} d r_{2} d r_{3} d r_{4} \\
& \sum\left(\frac{1}{\omega_{m n}+\omega_{\alpha_{s}}}+\frac{1}{\omega_{m n}-\omega_{\alpha_{s}}}\right) \Psi_{\alpha}^{+}\left(r_{1}\right) \Psi_{m}^{+}\left(r_{2}\right) \Psi_{s}^{+}\left(r_{3}\right) .
\end{aligned}
$$




$$
\begin{gathered}
\cdot \Psi_{n}^{+}\left(r_{4}\right)\left(1-\alpha_{1} \alpha_{2}\right) / r_{12} \cdot\left\{\left[\left(\alpha_{3} \alpha_{4}-\left(\alpha_{3} n_{34}\right)\left(\alpha_{4} n_{34}\right)\right) / r_{34} .\right.\right. \\
\sin \left[\omega_{\alpha_{n}}\left(r_{12}+r_{34}\right)+\omega_{\alpha_{n}} \cdot \cos \left[\omega_{\alpha_{n}}\left(r_{12}+r_{34}\right)\right]\left(1+\left(\alpha_{3} n_{34}\right)\right.\right. \\
\left.\left.\left.\left(\alpha_{4} n_{34}\right)\right)\right]\right\} \Psi_{m}\left(r_{3}\right) \Psi_{\alpha}\left(r_{4}\right) \Psi_{n}\left(r_{2}\right) \Psi_{s}\left(r_{1}\right)
\end{gathered}
$$

Expression (6) can be represented as an a sum:

$$
\Sigma\left\langle\alpha m\left|W_{1}\right| n s\right\rangle\left\langle s n\left|W_{2}\right| m \alpha\right\rangle /\left(\omega_{m n} \pm \omega_{\alpha s}\right)
$$

with (4) different operator combinations $W_{l}$, $W_{2}$. The sum over $n$ can be calculated by the method of differential equations. The index $m$ numbers a finite number of states occupied in the core and the state of the real continuum. The continuum-related part describes the vacuum polarization of the electron field and leads to divergent integrals in the nonrenormalizable theory. Its contribution to the main contribution has an additional order of smallness $\left(\alpha Z^{2}\right)$. The minimization of the density functional $\operatorname{Im} \delta E$ leads to the integral differential equation for the $\rho_{\mathrm{c}}$, that can be numerically solved. This step allows to determine the optimization parameter $b$. In Ref. [8] the authors elaborated a simplified computational procedure.

The contribution of the main exchangecorrelation (the second and higher orders of the atomic perturbation theory or fourth etc ones of the QED perturbation theory) to imaginary part of an electron energy shift is determined by the polarizability of an atomic core, which is related to the electronic core density $\rho_{c}$. The expression (6) can be represented an a functional of the density $\rho_{c}$.

Under calculating the matrix elements (2) one should use the expansion for potential $\sin |\omega| r_{12} / r_{12}$ on spherical functions as follows [16-20]:

$$
\frac{\sin |\omega| r_{12}}{r_{12}}=\frac{\pi}{2 \sqrt{r_{1} r_{2}}} \sum_{\lambda=0}^{\infty}(\lambda) J_{\lambda+1 / 2}\left(|\omega| r_{1}\right) J_{\lambda+1 / 2}\left(|\omega| r_{2}\right) P_{\lambda}\left(\boldsymbol{\operatorname { c o s }} \widehat{\left.r_{1} r_{2}\right)}\right.
$$

where $J$ is the Bessel function of first kind and $(\lambda)=2 \lambda+1$. Substitution of the expansion (5) to matrix element of interaction gives as follows [14]:

$$
\begin{aligned}
V_{1234}^{\omega}= & {\left[\left(j_{1}\right)\left(j_{2}\right)\left(j_{3}\right)\left(j_{4}\right)\right]^{1 / 2} \sum_{\lambda \mu}(-1)^{\mu}\left(\begin{array}{cc}
j_{1} j_{3} & \lambda \\
m_{1}-m_{3} & \mu
\end{array}\right) \times } \\
& \times \operatorname{Im}\left\{Q_{\lambda}^{Q u l}(1234)+Q_{\lambda}^{B r}(1234)\right],
\end{aligned}
$$

where $j_{i}$ is the total single electron momentums, $m_{i}$ - the projections; $Q^{Q u l}$ is the Coulomb part of interaction, $Q^{B r}$ - the Breit part. Their detailed definitions are presented in Refs. [10-11,18,19]. The relativistic wave functions are calculated by solution of the Dirac equation with the potential, which includes the "outer electron- ionic core" potential and exchange-polarization potential [20]. In fact, we realize the procedure of optimization of relativistic orbitals base. The main idea is based on using ab initio optimization procedure, which is reduced to minimization of the gauge dependent multielectron contribution $\operatorname{Im} \Delta E_{\text {ninv }}$ of the lowest QED PT corrections to the radiation widths of atomic levels. According to $[11,18]$, "in the fourth order of QED PT (the second order of the atomic PT) there appear the diagrams, whose contribution to the $\operatorname{Im} \Delta E_{\text {ninv }}$ accounts for correlation effects and this contribution is determined by the electromagnetic potential gauge (the gauge dependent contribution)". The accurate procedure for minimization of the functional $\operatorname{Im} \delta \mathrm{E}_{\text {ninv }}$ leads to the DiracKohn-Sham-like equations for the electron density that are numerically solved by the Runge-Cutta standard method It is very important to know that the regular realization of the total scheme allows to get an optimal set of the 1QP functions and more correct results in comparison with so called simplified one, which has been used in Refs. [1113] and reduced to the functional minimization using the variation of the correlation potential parameter $b$. Other details can be found in Refs. [8,16,17].

The adequate, precise computation of radiative parameters of the heavy Rydberg alkali-metal atoms within relativistic perturbation theory requires an accurate accounting for the multi-electron exchange-correlation effects (including polarization and screening effects, a continuum pressure etc). These effects within our approach are treated as the effects of the perturbation theory second and 
higher orders. Using the standard Feynman diagrammatic technique one should consider two kinds of diagrams (the polarization and ladder ones), which describe the polarization and screening exchange-correlation effects. The detailed description of the polarization diagrams and the corresponding analytical expressions for matrix elements of the polarization interelectron interaction (through the polarizable core of an alkali atom) potential is presented in Refs. [16-40].

An effective approach to accounting for the polarization diagrams contributions is in adding the effective two-quasiparticle polarizable operator into the perturbation theory first order matrix elements. In Ref. [21] the corresponding non-relativistic polarization functional has been derived. More correct relativistic expression has been presented in the Refs. $[22,8]$ and used in our theory.

The corresponding two-quasiparticle polarization potential looks as follows:

$$
\begin{aligned}
& V_{p o l}^{d}\left(r_{1} r_{2}\right)=X\left\{\int \frac{d r^{\prime}\left(\rho_{c}^{(0)}\left(r^{\prime}\right)\right)^{1 / 3} \theta\left(r^{\prime}\right)}{\left|r_{1}-r^{\prime}\right| \cdot\left|r^{\prime}-r_{2}\right|}-\right. \\
& \left.-\int \frac{d r^{\prime}\left(\rho_{c}^{(0)}\left(r^{\prime}\right)\right)^{1 / 3} \theta\left(r^{\prime}\right)}{\left|r_{1}-r^{\prime}\right|} \int \frac{d r^{\prime \prime}\left(\rho_{c}^{(0)}\left(r^{\prime \prime}\right)\right)^{1 / 3} \theta\left(r^{\prime \prime}\right)}{\left|r^{\prime \prime}-r_{2}\right|} /\left\langle\left(\rho_{c}^{(0)}\right)^{1 / 3}\right\rangle\right\}
\end{aligned}
$$

$$
\begin{gathered}
\left\langle\left(\rho_{c}^{(0)}\right)^{1 / 3}\right\rangle=\int d r\left(\rho_{c}^{(0)}(r)\right)^{1 / 3} \theta(r), \\
\theta(r)=\left\{1+\left[3 \pi^{2} \cdot \rho_{c}^{(0)}(r)\right]^{2 / 3} / c^{2}\right\}^{1 / 2},
\end{gathered}
$$

where $\rho_{c}^{0}$ is the core electron density (without account for the quasiparticle), $\mathrm{X}$ is numerical coefficient, $\mathrm{c}$ is the light velocity. The contribution of the ladder diagrams (these diagrams describe the immediate interparticle interaction) is summarized by a modification of the perturbation theory zeroth approximation mean-field central potential (look $[2,8]$ ), which includes the screening (anti-screening) of the core potential of each particle by the two others. All computing was performed with using the modified PC code "Superatom-ISAN" (version 93).

\section{Results and conclusion}

We applied the above described approach to compute the oscillator strengths (reduced dipole matrix elements) for a number of transitions in spectra of the heavy alkali atoms and corresponding ions.

In table 1 we list our computational results on the wavelengths and oscillator strengths gf (upper number in the line "Our work": data, obtained without using the optimized basis set and accounting for the exchangepolarization corrections; lower number in the line "Our work" - with using the optimized basis set and accounting for the exchangepolarization corrections) for $1 \mathrm{~s}^{2} 2 \mathrm{~s}\left({ }^{2} \mathrm{~S}_{1 / 2}\right) \rightarrow$ $1 \mathrm{~s}^{2} 3 \mathrm{p}\left({ }^{2} \mathrm{P}_{1 / 2}\right)$ transitions in the Li-like ions with $Z=21,22$. In Table 1 the data on the wavelengths, oscillator strengths, calculated by Banglin Deng et al [12] (in the framework of the relativistic configurationinteraction formalism using multiconfiguration DF wave functions and considering the Breit interaction, QED and nuclear mass corrections), Zhang et al (the Dirac-Fock-Slater method and disturbed wave approximation), Martin et al (the relativistic quantum defect method),Nahar (ab initio calculations including relativistic effects employing the BreitPauli R-matrix method) and the NIST data [10-15] are listed too. The data by Banglin Deng et al [12] are obtained in the length gauge, and the ratios $(\mathrm{V} / \mathrm{L}$; in $\%)$ of the velocity and length gauges data to check the accuracy of calculations are listed. We also present our values of the gauge non-invariant contribution (Ninv; in \%). Comparison of the presented data shows that the agreement between the theoretical data and experimental results is more or less satisfactory. An estimate of the gauge-non-invariant contributions (the difference between the oscillator strengths values calculated with using the transition operator in the form of "length" G1 and "velocity" G2) is about $0.1 \%$. The theoretical data, obtained with using the different photon propagator gauges 
(Coulomb and Babushkin ones) are practically equal.

Table 1.

The calculated wavelengths, oscillator strengths for $1 \mathrm{~s}^{2} 2 \mathrm{~s}\left({ }^{2} \mathrm{~S}_{1 / 2}\right) \rightarrow 1 \mathrm{~s}^{2} 3 \mathrm{p}\left({ }^{2} \mathrm{P}_{1 / 2}\right)$ transitions in the Li-like ions with $\mathrm{Z}=28,30$; $\mathrm{V} / \mathrm{L}$ is the ratios of the velocity and length gauges values by Banglin Deng et al [12]; Ninv (in \%) is the gauge non-invariant contribution (this work);

\begin{tabular}{|c|c|c|c|c|}
\hline $\mathrm{Z}$ & Ref. & $\begin{array}{l}\text { Wave- } \\
\text { length } \\
\text { (A) }\end{array}$ & $\begin{array}{c}\text { Oscillator } \\
\text { strength } \\
\left(\mathrm{gf}, 10^{-1}\right)\end{array}$ & $\begin{array}{c}\mathrm{V} / \mathrm{L} ; \\
\text { Ninv }(\%)\end{array}$ \\
\hline \multirow[t]{6}{*}{28} & $\begin{array}{c}\text { Banglin } \\
\text { Deng et al }\end{array}$ & 9.104 & 1.2889 & $\mathrm{~V} / \mathrm{L} \sim 0.2$ \\
\hline & NIST & 9.105 & - & \\
\hline & $\begin{array}{c}\text { Zhang et } \\
\text { al }\end{array}$ & 9.099 & 1.299 & \\
\hline & Nahar & 9.1 & 1.339 & \\
\hline & $\begin{array}{l}\text { Martin } \\
\text { et al }\end{array}$ & & 1.28 & \\
\hline & This work & 9.103 & $\begin{array}{l}1.3285 \\
1.2891\end{array}$ & $\mathrm{~N}_{\mathrm{inv}} \sim 0.1$ \\
\hline \multirow[t]{5}{*}{30} & $\begin{array}{c}\text { Banglin } \\
\text { Deng et al }\end{array}$ & 7.859 & 1.2983 & $\mathrm{~V} / \mathrm{L} \sim 0.2$ \\
\hline & $\begin{array}{c}\text { Zhang } \\
\text { et al }\end{array}$ & 7.854 & 1.309 & \\
\hline & $\begin{array}{c}\text { Martin } \\
\text { et al }\end{array}$ & & 1.29 & \\
\hline & $\begin{array}{c}\text { This } \\
\text { work }\end{array}$ & 7.858 & $\begin{array}{l}1.3387 \\
1.2985\end{array}$ & $\mathrm{~N}_{\mathrm{inv}} \sim 0.1$ \\
\hline & $\begin{array}{c}\text { Banglin } \\
\text { Deng et al }\end{array}$ & 7.859 & 1.2983 & $\mathrm{~V} / \mathrm{L} \sim 0.2$ \\
\hline
\end{tabular}

\section{References}

[1] Grant, I. Relativistic Quantum Theory of Atoms and Molecules. Oxford, 2007.

[2] Glushkov, A., Khetselius, O., Svinaren-ko, A., Buyadzhi, V. Spectroscopy of autoionization states of heavy atoms and multiply charged ions. Odessa: 2015.

[3] Khetselius, O.Yu. Relativistic Energy Approach to Cooperative Electron- $\gamma$ Nuclear Processes: NEET Effect In
Quantum Systems in Chemistry and Physics, Series: Progress in Theoretical Chemistry and Physics; Nishikawa, K., Maruani, J., Brändas, E., DelgadoBarrio, G., Piecuch, P., Eds.; Springer: Dordrecht, 2012; Vol. 26, pp 217-229.

[4] Khetselius, O.Yu. Relativistic perturbation theory calculation of the hyperfine structure parameters for some heavyelement isotopes. Int. Journ. Quant.Chem. 2009, 109, 3330-3335.

[5] Khetselius, O.Yu. Relativistic calculation of the hyperfine structure parameters for heavy elements and laser detection of the heavy isotopes. Phys.Scripta. 2009, 135, 014023.

[6] Chernyakova, Y., Ignatenko, A., Vitavetskaya, L.A. Sensing the tokamak plasma parameters by means high resolution x-ray theoretical spectroscopy method: new scheme. Sensor Electr. and Microsyst. Techn. 2004, 1, 20-24.

[7] Dzuba, V.A., Flambaum, V.V., Sushkov, O.P. Calculation of energy levels, E1 transition amplitudes, and parity violation in Fr Phys. Rev. A. 1995, 51, 3454.

[8] Khetselius, O.AYu., Mykhailov, A.L., Efimova, E.A., Serga, R.E., Wavelengths and oscillator strengths for Li-like multicharged ions within relativistic many-body perturbation theory. Photoelectronics. 2018, 27, 69-78

[9] Safronova, U., Johnson, W., Derevianko, A. Relativistic many-body calculations of energy levels, hyperfine constants, electric-dipole matrix elements, and static polarizabilities for alkalimetal atoms. Phys. Rev. A. 1999, 60, 4476.

[10] Zhang, H.L.; Sampson, D.H.; Fontes, C.J. Relativistic distorted-wave collision strengths and oscillator strengths for the $85 \mathrm{Li}$-like ions with $8<Z<92$. Atom. Dat. Nucl. Dat. Tabl. 1990, 44, 31-77.

[11] Nahar, S. N. Relativistic fine structure oscillator strengths for Li-like ions: $\mathrm{C}$ IV - Si XII,SXIV,ArXVI,CaXVIII,Ti 
XX,Cr XXII, Ni XXVI. Astr. and Astrophys. 2002. 389, 716-728.

[12] Banglin, Deng.; Gang, Jiang; Chuanyu Zhang. Relativistic configurationinteraction calculations of electric dipole $n=2-n=3$ transitions for medium-charge Li-like ions. Atom. Dat. and Nucl. Dat. Tabl. 2014, 100, 1337-1355.

[13] Svinarenko, A., Khetselius, O., Buyadzhi, V., Florko, T., Zaichko,P., Ponomarenko, E. Spectroscopy of Rydberg atoms in a Black-body radiation field: Relativistic theory of excitation and ionization. J. Phys.: Conf. Ser. 2014, 548, 012048.

[14] Ivanov, L.N., Ivanova, E.P., Aglitsky, E. Modern trends in the spectroscopy of multicharged ions. Phys. Rep. 1988, 166.

[15] Ivanov, L.N.; Ivanova, E.P.; Knight, L. Energy approach to consistent QED theory for calculation of electroncollision strengths: Ne-like ions. Phys. Rev. A. 1993, 48, 4365-4374.

[16] Glushkov, A.V.; Ivanov, L.N.; Ivanova, E.P. Autoionization Phenomena in Atoms. Moscow University Press, Moscow, 1986, 58-160

[17] Glushkov, A.V.; Ivanov, L.N. Radiation decay of atomic states: atomic residue polarization and gauge noninvariant contributions. Phys. Lett. A 1992 , 170, 33-36.

[18] Glushkov A.V.; Ivanov, L.N. DC strong-field Stark effect: consistent quantum-mechanical approach. J. Phys. B: At. Mol. Opt. Phys. 1993, 26, L379386.

[19] Glushkov, A.V. Relativistic Quantum theory. Quantum mechanics of atomic systems. Astroprint: Odessa, 2008.

[20] Ivanova, E., Glushkov, A. Theoretical investigation of spectra of multicharged ions of F-like and Ne-like isoelectronic sequences. J. Quant. Spectr. and Rad. Tr. 1986, 36(2), 127-145.

[21] Ivanova, E.P., Ivanov, L.N., Glushkov, A., Kramida, A. High order corrections in the relativistic perturbation theory with the model zeroth approximation,
Mg-Like and Ne-Like Ions. Phys. Scripta 1985, 32, 513-522.

[22] Glushkov, A.V. Relativistic polarization potential of a many-electron atom. Sov. Phys. Journal. 1990, 33(1), 1-4.

[23] Glushkov, A.V. Negative ions of inert gases. JETP Lett. 1992, 55, 97-100.

[24] Glushkov, A.V. Energy approach to resonance states of compound superheavy nucleus and EPPP in heavy nuclei collisions In Low Energy Antiproton Physics; Grzonka, D., Czyzykiewicz, R., Oelert,W., Rozek, T., Winter, P., Eds.; AIP: New York, AIP Conf. Proc. 2005, 796, 206-210.

[25] Glushkov, A.V. Spectroscopy of cooperative muon-gamma-nuclear processes: Energy and spectral parameters $J$. Phys.: Conf. Ser. 2012, 397, 012011

[26] Glushkov, A.V. Advanced Relativistic Energy Approach to Radiative Decay Processes in Multielectron Atoms and Multicharged Ions. In Quantum Systems in Chemistry and Physics: Progress in Methods and Applications, Series: Progress in Theoretical Chemistry and Physics; Nishikawa, K., Maruani, J., Brandas, E., Delgado-Barrio, G., Piecuch, P., Eds.; Springer: Dordrecht, 2012; Vol. 26, pp 231-252.

[27] Glushkov, A.V. Multiphoton spectroscopy of atoms and nuclei in a laser field: Relativistic energy approach and radiation atomic lines moments method. Adv. in Quantum Chem. 2019, 78, 253-285.

[28] Khetselius, O.Yu. Quantum structure of electroweak interaction in heavy finite Fermi-systems. Astroprint: Odessa, 2011

[29] Khetselius, O.Yu. Optimized relativistic many-body perturbation theory calculation of wavelengths and oscillator strengths for Li-like multicharged ions. Adv. Quant. Chem. 2019, 78, 223-251.

[30] Khetselius, O.Yu. Relativistic Hyperfine Structure Spectral Lines and Atomic Parity Non-conservation Effect in Heavy Atomic Systems within QED 
Theory. AIP Conf. Proceedings. 2010, 1290(1), 29-33.

[31] Khetselius, O.Yu. Relativistic Calculating the Spectral Lines Hyperfine Structure Parameters for Heavy Ions. AIP Conf. Proc. 2008, 1058, 363-365.

[32] Khetselius, O.Yu. Hyperfine structure of radium. Photoelectronics. 2005, 14, 83-85.

[33] Khetselius, O.Yu.; Gurnitskaya, E.P. Sensing the electric and magnetic moments of a nucleus in the N-like ion of Bi. Sensor Electr. and Microsyst. Techn. 2006, 3, 35-39.

[34] Khetselius O.Yu.; Gurnitskaya, E.P. Sensing the hyperfine structure and nuclear quadrupole moment for radium. Sensor Electr. and Microsyst. Techn. 2006, 2, 25-29.

[35] Khetselius, O.Yu. Atomic parity nonconservation effect in heavy atoms and observing $\mathrm{P}$ and $\mathrm{PT}$ violation using NMR shift in a laser beam: To precise theory. J. Phys.: Conf. Ser. 2009, 194, 022009

[36] Khetselius, O.Yu. Quantum Geometry: New approach to quantization of quasistationary states of Dirac equation for superheavy ion and calculating hyperfine structure parameters. Proc. Int. Geometry Center. 2012, 5(3-4), 39-45.

[37] Glushkov, A.V. Relativistic and correlation effects in spectra of atomic systems. Astroprint: Odessa, 2006.

[38] Khetselius, O.Yu. Hyperfine structure of atomic spectra.- Odessa: Astroprint, 2008

[39] Glushkov, A., Buyadzhi, V., Svinarenko, A., Ternovsky, E. Advanced relativistic energy approach in electroncollisional spectroscopy of multicharged ions in plasma. Concepts, Methods, Applications of Quantum Systems in Chemistry and Physics (Springer). 2018, 31, 55-69.

[40] Dubrovskaya, Yu., Khetselius, O.Yu., Vitavetskaya, L., Ternovsky, V., Serga, I. Quantum chemistry and spectroscopy of pionic atomic systems with accounting for relativistic, radiative, and strong interaction effects. Adv. Quantum Chem. 2019, 78, 193-222.

[41] Khetselius, O.Yu., Glushkov, A.V., Dubrovskaya, Yu., Chernyakova, Yu., Ignatenko, A., Serga, I., Vitavetskaya, L. Relativistic quantum chemistry and spectroscopy of exotic atomic systems with accounting for strong interaction effects. In Concepts, Methods and Applications of Quantum Systems in Chem. and Phys. Springer. 2018, 31, 71 .

[42] Buyadzhi, V., Kuznetsova, A., Buyadzhi, A., Ternovsky, E.V., Tkach, T.B. Advanced quantum approach in radiative and collisional spectroscopy of multicharged ions in plasmas. $A d v$. in Quant. Chem. 2019, 78, 171-191.

[43] Ignatenko, A.V. Probabilities of the radiative transitions between Stark sublevels in spectrum of atom in an DC electric field: New approach. Photoelectronics, 2007, 16, 71-74.

[44] Khetselius, O.Yu., Lopatkin, Yu.M., Dubrovskaya, Yu.V, Svinarenko, A.A. Sensing hyperfine-structure, electroweak interaction and parity nonconservation effect in heavy atoms and nuclei: New nuclear-QED approach. Sensor Electr. and Microsyst. Techn. 2010, 7(2), 11-19.

[45] Glushkov, A.V.; Ambrosov, S.V.; Ignatenko, A.V. Non-hydrogenic atoms and Wannier-Mott excitons in a DC electric field: Photoionization, Stark effect, Resonances in ionization continuum and stochasticity. Photoelectronics, 2001, 10, 103-106.

[46] Glushkov, A.V.; Gurskaya, M.Yu.; Ignatenko, A.V.; Smirnov, A.V.; Serga, I.N.; Svinarenko, A.A.; Ternovsky, E.V. Computational code in atomic and nuclear quantum optics: Advanced computing multiphoton resonance parameters for atoms in a strong laser field. J. Phys.: Conf. Ser. 2017, 905, 012004.

[47] Danilov, V., Kruglyak, Y., Pechenaya, V. The electron density-bond order matrix and the spin density in the restrict- 
ed CI method. Theor. Chim. Act. 1969, 13(4), 288-296.

[48] Kruglyak, Yu. Configuration interaction in the second quantization representation: basics with application up to full CI. ScienceRise. 2014, 4(2), 98-115.

[49] Buyadzhi, V.V., Chernyakova, Yu.G., Antoshkina, O., Tkach, T. Spectroscopy of multicharged ions in plasmas: Oscillator strengths of Be-like ion Fe. Photoelectronics. 2017, 26, 94-102.

[50] Malinovskaya, S.V., Dubrovskaya, Yu.V., Zelentzova, T.N. The atomic chemical environment effect on the $b$ decay probabilities: Relativistic calculation. Herald of Kiev Nat. Univ. Ser.: Phys.-Math. 2004, N4, 427-432.

[51] Bystryantseva, A., Khetselius, O.Yu., Dubrovskaya, Yu., Vitavetskaya, L.A., Berestenk, A.G. Relativistic theory of spectra of heavy pionic atomic systems with account of strong pion-nuclear interaction effects: ${ }^{93} \mathrm{Nb},{ }^{173} \mathrm{Yb},{ }^{181} \mathrm{Ta}$, ${ }^{197}$ Au. Photoelectronics. 2016, 25, 56-61.

[52] Buyadzhi, V., Zaichko, P., Antoshkina, O., Kulakli, T., Prepelitsa, P., Ternovsky, V., Mansarliysky, V. Computing of radiation parameters for atoms and multicharged ions within relativistic energy approach: Advanced Code. J. Phys.: Conf. Ser. 2017, 905(1), 012003.

[53] Glushkov, A.V., Khetselius, O.Yu., Svinarenko, A., Buyadzhi, V. Methods of computational mathematics and mathematical physics TES: Odessa, 2015

[54] Ignatenko, A.V., Svinarenko, A.A., Prepelitsa, G.P., Perelygina, T.B. Optical bi-stability effect for multi-photon absorption in atomic ensembles in a strong laser field. Photoelectronics. 2009, 18, 103-105.

PACS 31.15.A-; 32.30.-r

Khetselius O.Yu., Mykhailov, A.L.

\section{RELATIVISTIC CALCULATION OF WAVELENGTHS AND E1 OSCILLATOR STRENGTHS IN Li-LIKE MULTICHARGED IONS AND GAUGE INVARIANCE PRINCIPLE}

Summary. The spectral wavelengths and oscillator strengths for $1 s^{2} 2 s\left({ }^{2} S_{1 / 2}\right) \rightarrow 1 s^{2} 3 p$ $\left({ }^{2} \mathrm{P}_{1 / 2}\right)$ transitions in the Li-like multicharged ions with the nuclear charge $\mathrm{Z}=28,30$ are calculated on the basis of the combined relativistic energy approach and relativistic many-body perturbation theory with the zeroth order optimized Dirac-Kohn-Sham one-particle approximation and gauge invariance principle performance. The comparison of the obtained results with available theoretical and experimental (compilated) data is performed. The important point is linked with an accurate accounting for the complex exchange-correlation (polarization) effect contributions and using the optimized one-quasiparticle representation in the relativistic manybody perturbation theory zeroth order that significantly provides a physically reasonable agreement between theory and precise experiment

like ions

Key words: relativistic theory, radiative transitions, gauge invariance principle, lithium- 
Хецелиус О.Ю., Михайлов А.Л.

\title{
РЕЛЯТИВИСТСКИЙ РАСЧЕТ ДЛИН ВОЛН И Е1 СИЛ ОСЦИЛЛЯТОРОВ В LI- ПОДОБНЫХ МНОГОЗАРЯДНЫХ ИОНАХ И ПРИНЦИП КАЛИБРОВОЧНОЙ ИНВАРИАНТНОСТИ
}

\begin{abstract}
Резюме. Спектральные длины волн и силы осцилляторов для переходов $1 \mathrm{~s}^{2} 2 \mathrm{~s}\left({ }^{2} \mathrm{~S}_{1 / 2}\right) \rightarrow 1 \mathrm{~s}^{2} 3 \mathrm{p}\left({ }^{2} \mathrm{P}_{1 / 2}\right)$ в Li-подобных ионах с зарядом ядра $\mathrm{Z}=28,30$ вычислены на основе комбинированного релятивистского энергетического подхода и релятивистской многочастичной теории возмущений с дирак-кон-шэмовским одночастичным нулевым приближением и условием соблюдения принципа калибровочноъ инвариантности в радиационных переходах. Проведено сравнение полученных результатов с имеющимися теоретическими и экспериментальными данными. Важный момент связан с аккуратным учетом вкладов сложных многочастичных обменных корреляционных (поляризационных) эффектов и с использованием оптимизированного одноквазичастичного представления в нулевом приближении релятивистской многочастичной теории возмущений, что определяет определенное согласие теории и эксперимента.

Ключевые слова: релятивистская теория, радиационные переходы, принцип калибровочной инвариантности, литий-подобные ионы
\end{abstract}

PACS 31.15.A-; 32.30.-r

Хецелиус О.Ю., Михайлов О.Л.

\section{РЕЛЯТИВІСТСЬКИЙ РОЗРАХУНОК ДОВЖИН ХВИЛЬ І Е1 СИЛ ОСЦИЛЯТОРІВ В Lі-ПОДІБНИХ БАГАТОЗАРЯДНИХ ІОНАХ ТА ПРИНЦИП КАЛІБРУВАЛЬНОЇ IHBAPIAHTHOCTI}

Резюме. Спектральні довжини хвиль і сили осциляторів для переходів $1 \mathrm{~s}^{2} 2 \mathrm{~s}\left({ }^{2} \mathrm{~S}_{1 / 2}\right) \rightarrow$ $1 \mathrm{~s}^{2} 3 \mathrm{p}\left({ }^{2} \mathrm{P}_{1 / 2}\right)$ в Li-подібних багатозарядних іонах з зарядом ядра $Z=28,30$ обчислені на основі комбінованого релятивістського енергетичнго підходу i релятивістської багаточастинкової теорії збурень $з$ дірак-кон-шемівським одночастинковим наближенням нульового порядку і умовою дотримання принципу калібровочно' інваріантності в радіаційних переходах. Проведено порівняння отриманих результатів 3 наявними теоретичними і експериментальними даними. Важливий момент пов'язаний з акуратним урахуванням внесків складних багаточасткових обмінних кореляційних (поляризаційних) ефектів і з використанням оптимізованого одноквазічастічного уявлення в нульовому наближенні релятивістської багаточастинкової теорії збурень, що визначає певну згоду теорії та експерименту.

Ключові слова: релятивістська теорія, радіаційні переходи, принцип калібрувальної інваріантності, літій-подібні іони 